\title{
Language Perception Model for Linguistics Teaching Di Yan
}

\author{
Qiqihar Medical University, Qiqihar, Heilongjiang, 161006, China
}

Key words: language perception model; linguistics; teaching; model

\begin{abstract}
Language perception is one of the basic connotations in the concept of psycholinguistics. It is a linguistic study of how language can be generated and transmitted under the influence of human perception. The study of language perception patterns dates to Europe in the nineteenth century, but the source of its professional research comes from the middle of the last century and has made significant progress in the discipline in a short time. Because of its high theoretical level of linguistics teaching, students cannot understand, which will need to put students as the main body to do a good job teaching. This paper discusses how to apply the language perception model in linguistic teaching from the perspective of language perception model.
\end{abstract}

\section{Introduction}

The theory of muscle of linguistics says that in the process of verbal recognition recognizing the speech signal is mainly dependent on the human speech when the specific activities of the muscle. The main speaker of the theory of muscle is Liberman, who argues that the same factor is different in terms of muscle movement and specific sound signals in different people or in different language environments. Such as the [b]factors in [bi:] and [be] from the physiological and phonological point of view, the two-specific voice is different. But both the hearer and the speaker are in the psychological identity of the two elements of the internal part of the same point is greater than the difference, it does not affect the communication, besides, the two are not within the scope of communication to further distinguish. The main idea of the theory of muscle motion is that during speech recognition, speech signals are identified by reference to muscle activity of speech. This theory links the process of speech and the process of verbal perception, because it emphasizes how we can recognize words according to how we produce words.

The basic idea of the logical model is that human beings first think from the point of view of their own logical thinking in the spread of language, to support the logic model of language perception mode of scholars that language generation, dissemination and existence of three processes, that is prominence, combination and identification. This model considers that the process of language listening recognition is uniform and specific. On the basis of various kinds of different manifestations, the joint process of distinguishing features from the beginning of language begins to 
operate, and the listener's voice in the memory according to the brain to match the information, and finally make a reasonable decision based on the matching results, so the process of information to hear come to the end [1]. It is a general description of the language of the unit, including the combination of various distinguishing features. The operation process begins with the input, the information is evaluated, and the prototype description matches the memory. Making decisions based on suitability.

The main proposition of the interaction model theory is Marslen-WiIson and his colleagues, who argue that the process of recognizing is the process of recognizing words, which is divided into two phases. In the first stage, the sound feature of the previous word activates the next word, such as the [baik], b, a, i, k, and so on. In the first stage, the words that interact with each other, in the second phase they will have an effect in the human brain and exclude other irrelevant vocabularies to produce the corresponding conceptual target words.

The analysis model mainly refers to the analysis of the process of listening comprehension by the method of synthesis, proposed by Stevens \& Halle in 1976, and has a certain internal relationship with the muscle model theory. The analysis model also advocates the study of speech generation mechanism and communication perception mechanism. It is argued that, according to the actual discourse heard by the listener to compare the implicitly generated understanding of the brain with the non-"synthetic" language in the physical transmission of hearing comparison to rationally analyze and identify words. Under this model theory, the analysis of the perception process is centered on the physical characteristics of the speech signal itself, and the purpose of distinguishing features of different discourses. It is like the theory of muscle motion is to link language and speech perception. It argues that the listener's words are implied by the words he has heard, and compares it with the "synthetic" speech of the auditory stimulus. According to this model, the perception process begins with analyzing the auditory characteristics of the speech signal and establishing a discourse representation that is characterized as a distinguishing feature.

Elman \& McClelland (1984) proposed a neural network model, which is built on a processing unit based on the system. Phonetic or distinguishing features, phonemes and words are nodes at different levels [2]. Each node has a sleep level. An upper bound and an activation level that represents the unit represented by the input and node, and the nodes in the system are interconnected. If a node reaches the upper limit, it will affect the other nodes connected to it.

\section{The reform model of linguistics teaching}

The basic idea of the teaching model of this course is that the whole teaching process should fully reflect the "student as the main body and teacher as guidance". It stressed that "self-learning of 
students are the main point, supplemented by teacher counseling." to carry out "inquiry" teaching model. "Inquiry" teaching model includes: the question as the starting point of teaching; teaching to explore activities; organizational variants training; timely feedback and evaluation. Exploratory textbook (questioning)- Knowledge of teaching materials (system teaching) - Consolidated knowledge (oral written exercises)- Use of knowledge (knowledge activation)- evaluation (student and teacher evaluation).

Teaching strategy is a kind ofthe teaching organization form, teaching methods, teaching links and other teaching behavior of a comprehensive implementation of the program to achieve the desired teaching effect. Teaching organization form: According to the strong characteristics of this course, from the actual teaching effect, the corresponding following teaching organization can be used; individualized self-learning; group learning, collaborative learning. Teaching means is kind of tools, media or equipment for teaching activities of teachers and students to communicate with each other. There are two types of teaching methods that can be used in this course: traditional means and modern information technology [3]. The teaching methods of this course can be used to explain, inquiry and so on. Teaching links: perception, understanding, practice, use and evaluation.

This course is not practical teaching links, so in the theory of teaching it should be fully reflected. “Guided learning "," self-study "," learning "and" promoting learning ", can be divided into three stages to organize students to learn. Under normal circumstances, about $40 \%$ of the total hours should be arranged as self-study time, about 30\% of the teaching time for teaching, and 30\% of the total time for the formation of assessment work, self-test, review and other links.

Individualized learning refers to the students in the network environment based on their own way to determine their own learning process, to complete the learning tasks, including the guidance of teachers to develop personal learning plans; to determine the appropriate learning methods, learning media, learning time and place; to make full use of the school to provide learning support services, self-study, and participate in group learning and centralized counseling; to actively participate in online discussions, telephone answering and other interactive teaching activities; to complete the various stages of the learning tasks and formative assessment; and to fill out the personal learning log, timely learning summary.

Collaborative learning is a learner who works together in a group form through interactive activities. As this course has a certain degree of difficulty in learning, it is difficult to achieve the intended purpose of teaching, collaborative learning is more suitable for learners to choose. The formation of learning groups is to determine the mode of activities, the development of group learning plan; to plan to take online or non-online way, real-time or non-real-time group learning activities; on time to complete the various stages of learning tasks; and timely to feedback teaching 
information.

Focus on learning. Mainly to solve the common learning with the wish, including two-way video counseling, face-to-face counseling, focused discussion.

\section{The application of language perception model in linguistics teaching}

The application of language perception in linguistic teaching requires that the basic framework of the curriculum first. First, the basic teaching framework of linguistics teaching should be in the current curriculum requirements of the new curriculum reform. Second, the basic idea of teaching framework should be student-centered, teacher counseling as an auxiliary part of the "inquiry-based" teaching model [4]. Finally, the "exploratory" teaching mode requires teachers to take the teaching problem as the starting point and the foothold, while explaining the basic knowledge at the same time pay attention to guide students to self-exploration. It should be noted that the basic framework of language perception mode application and linguistics teaching also requires teachers to guide students in a reasonable language to enhance the language proficiency of students.

After the teaching framework is established, to achieve the intended teaching purpose and improve the effect of language perception mode, teachers should adopt different specific teaching strategies according to the different courses, and design the teaching steps, organizational forms and specific teaching for the classroom, besides, before class they should design methods and a series of specific details, including the teaching strategy program [5]. Specific examples such as teaching methods are modern means and traditional means for teachers to choose; teaching links can be divided into perception, understanding, use and other specific links, but perception should be one of the most important part. Finally, the teaching organization forms include independent learning, group inquiry, teachers and students focus on learning and other forms.

The most important part is the teacher's practical design of teaching courses. First, linguistics teaching theory is stronger than other subjects, so the proportion of practice teaching and theoretical teaching should follow the "do not set practice teaching, fully embodies the theory of teaching" requirements [6]. In the theory of teaching, it should be based on the needs of students to set up "self", "guide" and "help" as three different stages of teaching step by step to improve their linguistics and language perception. Specifically, the general linguistics teaching requires students to self-study part of the time occupied by about 40 percent of the total course; teacher counseling time is about 30 percent; the remaining part of the time can be used for extracurricular counseling, homework Evaluation and a series of student activities. 


\section{Conclusion}

This article describes the five patterns of language perception, the result of each pattern is meaningful words, rather than meaningless syllables. Their purpose is to describe the interaction of phoneme recognition and word recognition. In short, the first three are point-to-point, line-to-line models that are flat models. While the last two are centered model which like a network. Finally, in the actual teaching, according to different ways of learning arrangements which require teachers to remind students to learn from different points of entry. For example, in individual self-learning, teachers should guide students from their own situation reasonable to use the network, books and other ways to self-study, and after a certain time interval to summarize the learning situation. In the case of mutual learning, students should be taught to discuss with each other the specific methods of group learning.

\section{Acknowlegement}

Project Source: The Social Science Fund of Qiqihar Medical University

Project Name: The Empirical Study on the Influence of Mother Language on the Second Language Word Acquisition. Item Number: QYSKL2015-08

\section{References:}

[1] Yang Xinlu, Zhang Juan. Study and Practice of Research Teaching in "English Linguistics" Course [J]. Chinese Journal of Foreign Languages Education, 2016, (08): 132-133.

[2] He Liping. Reflections on the Teaching of English Linguistics under the Background of the Transformation of Local Colleges[J]. Journal of Hunan University of Science and Technology, 2016 (07): 167-169.

[3] Xu Wei. Image-based Theory under the Guidance of College English Vocabulary Teaching Strategy Research [D]. Jilin University, 2016.

[4] Shi Zijuan. Student-centered Construction of College English Teaching Model from the Perspective of Internet of Things [J]. Journal of Knowledge, 2016, (04): 131-132. 